\title{
Making it Safe to Think Differently About Sex in the Academy
}

\author{
Dee Amy-Chinn \\ Westminster Institute of Education \\ Oxford Brookes University
}

$\underline{\text { Introduction }}$

How do we create a space in the Academy in which it is safe for our students to think differently about issues of gender and sexuality that are foundational to their existence in the world? Culture, Gender and Sexuality is an interdisciplinary module open to second and third year undergraduates at the Westminster Institute of Education at Oxford Brookes University. The Institute takes as its remit the promotion of study in the area of human development and learning, and is keen to promote interdisciplinary work. The explicit remit of the Culture, Gender and Sexuality module is "to critique traditional and static understandings of gender and sexuality, drawing on a diversity of disciplines, including those of gender studies, critical theory, queer theory, feminist theology and feminist criticism" (emphasis mine). It was developed to be taught in the fields of Theology and Religious Studies which, from 2006, will be amalgamated under the title Religion, Culture and Ethics, but given its inter-disciplinary nature it was made acceptable to students in the field of Communication, Media and Culture - many of whom (as evidenced by choice of assignment topics in other modules) have an interest in the subject area. The module sets out to destabilize notions of biological sex, 'trouble' gender (Butler: 1990) and open up debate around sexualities. In doing so the module (which runs for 12 weeks) seeks to challenge some of the most fundamental assumptions that govern our identities.

It was intended that while students would find the subject matter interesting and relevant they would also find it challenging at both an intellectual and ethical level. It was thought that the subject matter for the module - which includes discussion of what Plante (2006) has recently referred to as the "alphabet soup" of sexualities (including, but not limited to, lesbian, gay, trans, 
queer, questioning, sado-masochistic) - had built into it some controversial topics. So it was deemed important to create a safe space in which students could discuss and debate the issues raised and share openly their point of view. After all, dialogue is seen as central to all forms of liberatory, critical and feminist pedagogies - and dialogue cannot take place if students feel unable to speak.

The focus of the article will be the way in which this module was presented to students in the classroom in order to generate a sense of (at least temporary) safety, and to encourage open debate and honest discussion. It will address the information students were given in the module handbook to prepare them (both intellectually and ethically) for engagement with the module content. It will also cover their involvement in setting the criteria for the success of the module and the formulation of ground rules for student participation, these being designed to give the students a sense of ownership of the course and responsibility for their own learning. The intention in doing this was to foreground the teaching/learning relationship as one of (albeit unequal) partnership rather than transmission. Finally the article reflects on the effectiveness of these elements over the course of the module, and concludes with some thoughts on what might be done differently in future.

\section{Locating the Issue}

My sense that the subject matter in this module would be controversial, and that the classroom would not always feel a safe space, came from my experience as both student and teacher. In 1999 I returned to Higher Education after many years spent as a career civil servant where I had developed a particular interest and expertise in issues of equality and diversity. I embarked on a postgraduate course on gender and sexuality. My cohort comprised mainly mature students with a high degree of intrinsic motivation. However I was surprised by the extent to which such motivation did not go hand-in-hand with intellectual curiosity and a willingness to be open

to new ideas. It became clear early on that many of those enrolled on the course were seeking answers, or definitive guidance. Indeed, many students 
thought that questions of gender and sexuality (particularly gender) were 'common sense', so while they were prepared to undertake a certain amount of reading this was often confined to texts that offered academic support to what they already 'knew'.

In addition, homophobia and transphobia were sometimes evident in the classroom. A small (but frequently vocal) minority of students were quite open in expressing such views (see Eyre (1993) for a fuller account of a similar situation). Finally, and no doubt linked to the above, non-heterosexual students were not always comfortable in using their personal experience as a site from which to speak, even though the issue of partial and situated knowledges was foregrounded in the core module of the programme. As a student I was very conscious that one student never spoke of their personal experience as a transperson - even in classes that focussed on trans issues. Indeed that individual was not 'out' to the course and shared with me that they would not have felt comfortable acknowledging their status openly.

My experiences were similar when I began to teach gender and sexuality, and the evidence indicates that my experiences are not unique. Reflecting on her experiences of teaching a course on Introduction to Gender History in the urban environment of Detroit, Elaine Carey has noted, "everyone constantly engages in some form of gender analysis and criticism whether in their homes, at school, or standing in a check-out line skimming the fashion and gossip magazines" (2003:4). Carey's comment supports my observation that all students will approach a course on gender and sexuality with some sense that they are already familiar with the subject matter. It is, after all, impossible to go about one's everyday life without some sense of one's gender embodiment - Julia Collar notes "students are gendered bodies, replete with hormones, and are consequently sexual, and in some cases highly sexualised, individuals" (2000:165). Society is so rigidly constructed on the basis of the male/female binary (perhaps one of the last grand narratives left in the post-modernist world?) that being either male or female is critical to the subject's interpellation. The first question we ask of a new baby is "is it a boy or a girl?" And while Judith Butler has done more than most to question the 
foundational nature of this identification, even she does not suggest that an individual's gender identity can be changed at will (1993: x).

So while all students will approach issues of gender and sexuality with a sense of pre-existing knowledge "[t]ypically we are not talking about a sophisticated understanding of the contingent and constructed nature of these identities, but one based on stereotypes and media omniscience in television, film and music culture" (De Soto, 2005:212). Aureliano Maria DeSoto is writing as an openly gay and Latino professor who, in the spring of 2003, taught a course on lesbian and gay social formation from World War II to the present. Reflecting on his experiences of this course, DeSoto notes that his students' expectations were "not based on a quest for knowledge but, rather, in the pursuit of a reassertion of what is already known" (p. 214), and that the views they held were often both sexist and racist. De Soto's experiences as a teacher reflect my own experience as a postgraduate student and, subsequently, lecturer.

Carey and DeSoto had, as an explicit part of their agenda, a desire to have students critically analyse questions of gender (Carey, 2003: 4), challenge previous knowledge systems (DeSoto, 2005: 216), and in doing so to model new ways of looking. This parallels the agenda for my module which - as noted above - was developed with the specific remit that it should "critique traditional and static understandings of gender and sexuality". Carey acknowledges that this is a great demand to make of second and third year students (2003:4), although neither she nor DeSoto engage specifically with the fact that their demands are not just intellectual but are also ethical, and cannot be addressed successfully unless students are able to negotiate them through higher order thinking skills.

While neither Carey nor DeSoto mention the formation of ground rules as a way of negotiating the challenging subject matter they sought to tackle, both reflect on insights offered by their courses - and these have influenced my approach. Operating in the economically and ethnically diverse environment of Detroit, Carey notes that, influenced by the ideas of Paulo Freire, she 
sought to embrace the knowledge that her students brought to the classroom, inviting them to decide what intrigued them about gender (2003:4). Carey sought to empower students in the construction of the classes, which enabled them (if they wanted) to lead the discussion into areas such as gay studies, the history of contraception and the role of women in the church - all sensitive topics at the Catholic university in which the course was being run (p. 5). She notes that, at times, the topics were uncomfortable for some students, but concludes that providing a safe space where students could talk to one another about controversial subjects and ideas (while drawing on their own knowledge) led to some highly sophisticated analysis of gender-related issues (p.7).

Carey does not discuss how she created this "safe space", nor how she tackled questions of racism and sexism amongst the student body - assuming that such issues arose. Moreover, in Carey's case, she does not reflect on the challenges of asking students to speak from the position as 'informed experts' based on their embodiment. Given that the subject matter of her course was Gender History, with a focus on gender and race, this may not have been a problem as both gender and race are inscribed on the body. This is not true of sexuality. As noted above, DeSoto acknowledges his position as an openly gay professor. He also notes the burden that this brings - indeed the special burden that all those who teach in race and sexuality must confront - in that the tutor's presence as a raced and gendered body inevitably bears inordinate weight in student learning (2005:219). Drawing on the work of Joseph Litvak, DeSoto notes the way in which students often prefer to view their professor as a representation and not an individual. Thus, in the queer classroom, the professor - if they acknowledge their own embodiment as queer - can come to stand in for queer as a whole. De Soto quotes Litvak's observation that:

the students, especially the self-identified queer or bisexual students, seemed precisely to regard as invasive any attempt not to grant them the heterosexual privilege of spectatorial distance, and to resent any 
invitation to explore their encrypted desires and identifications. (Litvak in DeSoto, 2005: 213).

This observation calls into question the belief that it is easy to treat students as 'informed experts' and ask them to contribute to class on the basis of their embodiment - particularly if their status as 'informed expert' is based on the non-visible, i.e. on their sexuality rather than their gender or race. Moreover, both Litvak and DeSoto are writing from the perspective of professors who openly acknowledge their queer positionality. How much harder might it be to ask students to speak from their experiences as members of a marginalised group when the tutor is both white and heterosexual (as I am) - albeit one following in the steps of Eve Kosofsky Sedgwick ((1994) and Calvin Thomas (2000), neither of whom view queer as synonymous with gay/lesbian identity. Rather I adopt David Halperin's position, viewing queer as:

... by definition whatever is at odds with the normal, the legitimate, the dominant. There is nothing in particular to which it necessarily refers. It is an identity without an essence (1995:62).

On the positive side, such a position does enable me to foreground my own heterosexual privilege in a way intended to alert the students to their own (often unacknowledged) forms of privilege. It may also confer advantage in that students engage with the material I present without assuming that I am putting forward a particular political agenda. Yet I do have a significant political commitment to the issues raised by this module, and do not seek to hide my agenda of promoting openness and tolerance of difference, highlighting the often life-threatening consequences faced by many of those whose identity fails to conform to cultural expectations. Indeed, at the end of one class a student asked me how it felt to have the power to change lives. Hence while I do not profess a lesbian identity I do openly question my identity as 'female', and make no attempt to present a disembodied pedagogy. 
So how I choose to present myself is an important issue. After all, most students will approach a course that seeks to critique traditional and static understandings of gender and sexuality from a hegemonic perspective gained from parental, peer and media socialization. And those who fail to conform to the norms of a society in which heterosexuality is so ubiquitous that it goes unnamed as such, but is simply seen as 'normal', are unlikely to feel comfortable in asserting their status as 'informed experts' unless an explicitly safe space from which they may speak is created and they are able to anticipate a positive reception. But it also needs to be noted that simply presenting alternatives to traditional understanding will not necessarily lead to acceptance (and even acceptance may be more than can be achieved over a 12-week period). Writing on teaching Boys Don't Cry (Kimberly Peirce: 1999), a film that set out to offer a sympathetic representation of transperson Brandon Teena (who was raped and subsequently murdered when his 'true' sex was discovered - highlighting the dangers consequent upon nonconformity), Alexandra Barron notes the range of reactions students had to the film ranging from comments that Brandon was sick and diseased to identifying with Brandon and his pain (2003: 43). And Davis (2000: 347) has noted tbat "consciousness is not easily transformed even when "truth" is revealed" and "that there always exist emotional repressions, denials, and silences which resist rational self-control".

Speaking at a panel on queer pedagogies at the Queer Matters conference held at King's College London at the end of May 2004, DeSoto reflected that attempts to instil critical thinking in students who have an investment in narrative stability can generate resentment. Some students will be unable to make the journey, and that becomes one of the risks of the job. At this point it is also worth recalling that many of the students embarking on the Culture, Gender and Sexuality module will come from the fields of Theology and Religious Studies. While this does not, de facto, make them religious, it is worth recalling Collar's observation that subscribing to a religion "also necessarily entails subscribing to a code of morality and ethics that govern the interaction of the body with society" (2000: 165) and that this may conflict with some, if not all, of the secularized thinking that forms the basis of the course 
content (it should also be acknowledged that many of the students taking the module who were not actually studying Theology and/or Religion may also have held quite strong views based on their faith).

At the Queer Matters panel, seeking to offer practical advice to fellow academics teaching a queer curriculum, DeSoto suggested a student 'survey' at the beginning of the course to tease out expectations and fears. He also noted the importance of being willing to sacrifice content for process, and the importance of dealing with student needs rather than be guided by the need to work through the questions that, as tutor, you may want to address. As Kalwant Bhopal has noted (echoing the views of Elaine Carey discussed above) "giving students the space to discuss sensitive issues is the most effective role the lecturer can take" (2002: 114, emphasis in original). This advice chimes with encouraging a deep approach to learning where students attempt to relate concepts to existing experience, critically evaluating and determining key themes and concepts (Fry, Ketteridge and Marshall, 2003: 18). This, in turn, should lead to high levels of understanding with at least some students achieving what Fry et. al. have described as 'extended abstract' understanding where:

A coherent whole is conceptualised at a high level of abstraction and is applied to new and broader contexts. It is a level of understanding in which a breakthrough has been made and it changes the way of thinking about issues. (p. 20).

What becomes clear from the above is that any course that seeks to challenge students at the core of their being - their normative gender identity - and to destabilize notions of biological sex, gender and sexuality, is, if students engage deeply with the material, likely to lead to what Warren has described as "hot moments" in the classroom. These are moments "when people's feelings - often conflictual - rise to a point that threatens teaching and learning" (n.d. p. 1 of 4). Recognising the inevitability of such points the purpose in agreeing ground rules at the outset of the course is designed (a) to 
minimize such moments of tension and (b) to have an agreed strategy for dealing with such moments when they occur.

\section{U74124: Culture, Gender and Sexuality}

Considering it to be important to set the tone from the outset the module booklet provided a high degree of detail with regard to the course content. The strength of this was that it enabled students to see from the outset how the module fitted together and to have a clear idea of the route to be followed. One potential weakness was that it limited the scope for responding to specific student interests (see Carey 2003). However, feedback from other modules I have taught has indicated that students feel most comfortable when they can see the structure of the course they are taking. Given that some of the sessions may raise issues that students feel challenged by, the security of a clear and comprehensive handbook was intended to help allay anxiety by reassuring students that the tutor was in control of events. It also allowed me to provide detailed guidance on reading for each session that students could use to prepare in advance or follow up after the class. In addition it gave me a space to include web addresses for sites that I thought might be useful (such as that for the advocacy group the Intersex Society of North America) so that students had somewhere to go for more information should any of the classes have a particular resonance for them. Moreover, when I discussed with students their hopes for the module, and asked them to identify the factors that would make the module a success, both groups claimed to want a logical progression through the topics and to have a sense of structure, in respect of the whole module and individual classes. There was a particular fear that the interdisciplinary nature of the module would mean that it lacked coherence, that classes would not relate to one another and that, as students, they would lack any sense of progression.

From the outset the handbook was designed to lay the foundation for the establishment of ground rules. The first page offered an introduction which recognised that students would be approaching the module with a sense of familiarity with the subject matter, but asking them to be open to new 
approaches and new arguments. It stated, explicitly, that the willingness to be prepared to question received wisdom - to 'think differently' - would be a key element of the module and quoted Foucault:

There are times in life when the question of knowing if one can think differently than one thinks, and perceive differently than one sees, is absolutely necessary if one is to go on looking and reflecting at all. ... [W] hat is philosophy today ... if it is not the critical work that thought brings to bear on itself? In what does it consist, if not in the endeavour to know how and to what extent it might be possible to think differently, instead of legitimating what is already known? (Foucault, 1992: 8-9)

With specific regard to the question of ground rules, page one of the booklet stated that "one of the things we will do in our first week is to agree, as a group, ground rules for contributing to the course and for in-class behaviour". This is reinforced in the outline of the Week One class which states "we will spend some time agreeing rules for in-class behaviour to ensure that all students feel able to contribute to the discussion in a space that is safe, and tolerant of a wide range of experience and opinion". Following the advice of Warren, this approach allowed discussion norms to be established early in the course (n.d. page 2 of 4) and was intended to enable agreement to be reached on the importance of encouraging open discussion of difficult material.

DeSoto's suggestions regarding the need to tease out student expectations and fears and the importance of being willing to sacrifice content for process were addressed explicitly. Students were asked to work in groups (opening up small-scale discussions) to share their hopes and fears for the module, which were then shared by the class as a whole, in terms of what would make the module successful for all concerned and what might spoil it. These were recorded on flip-charts and were turned into a handout distributed to all students in Week Two, and reviewed both mid-Semester (as a lead-in to a mini-evaluation) and at the end of the module. In the light of the avowed aims of the module the success criteria that the students came up with were 
encouraging. The number of students who enrolled on the module (62) meant that they were taught in two groups (a morning and afternoon session on the same day).

Both groups indicated that they were keen to achieve deep, rather than surface, learning (and they formulated it using these terms), wanted to be challenged with new ideas, and to understand the viewpoint of others. One group spent quite a lot of time discussing the importance of learning something about themselves, having an increased awareness of 'difference' and understanding how stereotypes came about. Both groups were also keen to avoid having people be afraid to speak out and having people judged for their ideas. What they wanted to avoid was intolerance, narrow-mindedness, being afraid to express an opinion and not being given the time to explore the topics in sufficient depth. One group raised the issue of being subjected to verbal and/or physical violence.

Having agreed what would make the module a success and what would spoil it, the students were then invited to formulate some 'rules' that would maximize chances of success and minimize the possibility of failure.

The ground rules common to both classes were:

- We will encourage everyone to contribute to class.

a We will not judge people on the basis of their ideas.

- We will respect all contributions.

- We will critique ideas but never people.

- We will try and be open to the ideas and points of view of other people.

In addition to formulating 'rules' designed to create a safe space from which to explore a range of potentially challenging theories and ideas, the first class sought to introduce students to standpoint theory and issues of embodied epistemology. This encouraged students to address the relationship between our classed, raced and gendered bodies and the way in which we understand the world, and to instil a sense that different individuals will see the world 
differently depending on whether they are male/female, straight/gay, white/black (to formulate this in shorthand binary terms to which I am opposed). More abstractly the input was designed to lead in to an agreement that "all students seek to understand each other's perspectives, as a prerequisite to understanding the subject at all” (Warren, n.d. page 2 of 4). So students were asked from the outset to be open to the voice of others and to recognize not only their right to speak and be heard, but also to be conscious of their own privilege when listening.

Having formulated some basic ground rules the intention was that these rules would be foregrounded in each class. However, as it turned out there was very little controversy in the first few weeks and it felt false to keep revisiting the 'rules' when there were no issues. Indeed, it seemed to me this would be counter-productive and might lead students to be less accepting of new ideas if they thought they were expected to find them problematic and controversial. The issues we tackled in these weeks included the work of Anne FaustoSterling (2000) on multiple sexes, questions around intersex, a range of trans issues (transsexuality, transgender, transvestism). The thinking tools provided in Gayle Rubin's now-classic article 'Thinking Sex' (1992) were used to explore issues around a range of sexualities. In order to provide material for discussion I drew not only on a set of key readings but also on a range of visual texts and testimonies - both documentary and fictional.

My experience followed that reflected in the review of the literature. That is, while students were willing to contribute to discussion, very few did this from the perspective of 'informed experts' drawing on their own embodiment. Where this did happen - particularly in the first class - in which we discussed the meaning of embodied epistemology, was in respect of race. A small number of Black and Minority Ethnic (BME) students were politely dismissive of those White students who claimed to understand the nature of race discrimination (the class dealt explicitly with the issue of White as a colour in order that later in the module we could discuss heterosexuality as one of a range of sexualities rather than as a default position). Fortunately by this point in our (first) class we had come up with the basis of our ground rules, 
which certainly made the situation easier to handle by reminding students to challenge the idea and not the person.

However, on reflection, introducing questions of race at this point in the module was probably not helpful for two reasons. First it deflected attention from the issues of gender and sexuality that were intended as the focus of the module. More importantly, while race has some parallels with gender as an identity worn on the body, it differs from sexuality in that sexual identities can be kept hidden (albeit at often considerable personal cost). With this in mind one thing I will do differently next time the module runs is to attempt to tackle standpoint theory and related epistemological questions in the context of heterosexual privilege. One way of tackling this might be through use of selective questions from Martin Rochlin's now classic "Heterosexuality Questionnaire". This would require students to think about the types of questions that same-sex identified individuals are frequently faced with - such as the 'cause' of their heterosexuality, or how they could be sure of being heterosexual if they had no experienced of a same-sex relationship. Another way would be to get students to identify all the things they take for granted, but which are conferred by heterosexual privilege - such as holding hands with their partners in the street without fear of incurring violence.

Moreover that fact that debate did become heated in our first week, even if this was managed successfully, may have made some students uncomfortable and closed down discussion in the weeks immediately following. I should, perhaps, have sought feedback on this at the midSemester evaluation. As it was, this took the form of 'what should I do more/less of, what is about right?'. The vast majority of students (around $90 \%$ ) indicated that they were very happy with the module as it was, and no one expressed any concern about lack of discussion or feeling unable to put forward their point of view. Other comments indicated that the students liked the personal testimonies (from documentaries) and wanted more of this. Finally there were a couple of requests that I organise a course outing to the Rocky Horror show, which was coming to Oxford for a week towards the end 
of the module (we had spent part of an earlier class discussing how to 'label' Dr. Frank-N-Furter)..

Later in the module controversy arose in the classes related to multiculturalism and theology. In the multiculturalism class the most heated discussion arose in response to a short reading from Germaine Greer (1999: 120-123) in which she argues in favour of female circumcision (despite this being proscribed by the United Nations). This provoked a range of responses from students with a variety of backgrounds, including a young woman from one of the regions where infibulation is seen as a widespread practice, who discussed the very different views of herself and her cousins on this issue. It was, however, unusual to get this degree of personal testimony - and in most cases the testimony of those able to speak from an embodied perspective came from selective use of documentary footage.

There were, however, a number of advantages to the use of documentary and, sometimes, fictional footage. Linda Eyre (1993: 274) has written of the issues involved in exploiting friends as tokens of minority identity and has proposed (p. 281) that textbook (or visual text-based) analysis is less threatening for students than listening to the live voices of those engaged in consciousness raising. Such analysis can be safer for all concerned. Yet there was an element of self-disclosure in the class. One very interesting aspect was that the module attracted a number of mature students who were parents - and many reflected on, or shared, their concerns about their children (for example one student who thought that her teenage daughter was a lesbian unwilling to 'come out' to her mother, and another who had a young son who liked wearing dresses). These topics were discussed at a general level in class, and were the subject on one-to-one discussions (initiated by the student) following the end of the session. This does indicate that in a module such as this, even if the tutor does not carry the weight of representation (see Litvak and DeSoto earlier in this article) they do carry the weight of 'expert' in a practical as well as intellectual sense. Dealing with such expectations is always challenging and so knowing how to access key resources (and 
providing such information in the module handbook and in class handouts) needs to be considered from the outset.

As mentioned, the other 'hot' class was on feminist theology. This was to be expected as a number of the students on the module were reading Theology and I knew from conversations with colleagues than many of them held strong religious views. During this class it did become necessary to revisit, briefly, the ground rules and it was helpful to be able to separate the need to engage in conceptual thinking from the need to agree with everything being said. To give a specific example, one of the topics introduced during this class was Marcella Althaus-Reid's $(2000,2003,2004)$ concept of indecent theology that considers how we might reflect on the Virgin Mary and Christology from sexual stories taken from fetishism, leather lifestyles and transvestism. While the students were able to accept the intellectual argument that the search for God should embrace the lives of those subject to social and sexual exclusion, there was little engagement with pursuing what this might mean in practice. In (large) part this may be because I do not have an advanced theological/religious education and make it clear to students at the start of the module that my speaking position is that of a secular gender/sexuality theorist. So not pursuing the implications of Althaus-Reid's theology may well reflect my concern not to misrepresent what I see as an important progressive theology, rather than my students' unwillingness to engage with it.

The following quotes are taken from student feedback provided as part of the end of Semester evaluation. They indicate the extent to which the module was, overall, a huge success, and that the ground rules operated effectively. As can be seen, there were mixed views on the extent to which students felt able to contribute: two of the quotes (representative of a the overall tone of the feedback) indicate that the discussions were effective; one suggests otherwise (although this is the only negative comment on discussion from all the evaluations submitted). Nevertheless I take on board fully the desirability of getting more students to speak. 
"Completely challenged and changed some ideas I had ... make it compulsory!"

"[l was given] the opportunity to express an opinion and not be apprehensive about it."

[I particularly liked] the wide variety of methods and opinions discussed."

"I had great fun doing a module which at first I wasn't sure of. It felt very cutting edge."

I think [this module is] a very useful one. People need to know!"

"[I particularly liked] the discussion we were able to have. ... The communication between the lecturer and the students was fantastic."

"This module has challenged my preconceptions and allowed me to examine ideas and topics I had not considered before. I have really enjoyed this module, it is one of the most valuable that I have done both educationally and personally"

"[I would like] more class discussion. Set up class in circle. Maybe have one class on getting to know one another so that it is a really comfortable place, then more people would talk"

A colleague who teaches a module on Equality and Identity (that deals with issues of class, race and gender) told me that she gets her students to complete a 'personal history' sheet at the beginning of the module and to speak to this in the first class. While I see great value in this I am not convinced it is appropriate on a module that deals with sexuality - but I do intend to consider whether such an approach might be adopted in some form as a way of getting students to speak. However it should be noted that the field of Theology at Brookes chooses not to operate in a confessional mode and students, while expected to be open minded, are not expected to share 
issues of personal faith. This suggests that the approach I took on this module fitted well with the expectations that students were deriving from elsewhere in their studies.

\section{Thinking About The Future}

This module ran more smoothly and successfully than I anticipated. As can be seen from the student comments above, the participants on the module were introduced to a wide range of new ideas. Each week offered the opportunity to discuss the issues raised, and there was always spirited and lively discussion. Despite dealing with issues of embodied epistemology and the impossibility of not having a standpoint, for much of the time the students approached the topics from an 'anthropological' perspective - that is they functioned as informed and critical observers of the Other. Despite efforts to make the space as comfortable as possible no students chose to speak as 'informed experts' on any of the sexuality topics (although they were happy to do so in respect of gender), but in keeping with the non-confessional mode of the Field this should not be seen as a failure. Rather it is important to recognise that, however safe the classroom environment, lesbian, gay, trans and queer students will continue to live in a world in which individuals with non-normative sexualities are discriminated against and often persecuted.

Writing in 1993 Linda Eyre noted (p. 275) that "[f]earing reprisals, many lesbian and gay students and teachers continue to hide their sexuality, often with disastrous personal consequences". And while many may think of Higher Education as a liberal and tolerant space, a recent article in the Times Higher Education Supplement (Tysome, 2006: 56) based on research conducted by the AUT reported that in a survey of 800 staff at six universities carried out by Jeff Frank, professor of economics at Royal Holloway, only $46 \%$ of lesbian staff and one in six of his gay male respondents described themselves as 'out' at work, suggesting that even within the Academy space may not always be perceived as safe for those not identifying as heterosexual, and that harassment and bullying of such staff is rife. 
On controversial (but less embodied) topics, such as multiculturalism and the attitude of the Church to female sexuality, students were much more open in acknowledging their own point of view - while at the same time asking for input on alternatives approaches/opinions, which I was expected to provide. Steven Schadt (2000: 3/13) states that "Recognizing that a truly value-free stance is an illusion, the instructor must take positions on issues without silencing other classroom voices". More recently Judith Halberstam (2005: vii) has asked how we can combine an impassioned pedagogy with a principled commitment to abstract thinking. Teaching this module I was very aware of the extent to which my personal politics and commitment to a world more tolerant of queer identities pervaded the classroom and, because of the power relationship which must exist in the classroom, inevitably made it difficult for students who did not share my views on these issues to speak out.

On the basis of my experience with this module I am engaging with the following issues when considering what changes to make for next year:

a Considering a way of getting every student to speak in the first class. Personal histories may not be the way forward, but some equivalent approach should be considered.

a Being more explicit about the 'confessional'/'non-confessional' nature of the module. While making it clear that this is a space in which students should feel safe in speaking from the position of 'informed experts' be clearer about offering the opportunity to assess the testimony of third parties. This means being diligent in obtaining more third party testimonies, particularly in the form of documentary footage where students can engage with the testimony of individuals with a degree of critical distance that would not be possible with live testimony.

a Cutting the content of some sessions to provide more space for discussion, i.e. be prepared to sacrifice content for process to an even greater extent.

a Developing strategies to deal with students' deep engagement with the module content while protecting my own space (see Davis, 2000: 351 
on the importance of setting boundaries). As evidenced from the module feedback and a number of one-to-one discussions with students, this was a course in which they invested a great deal on a personal level. Students want, quite rightly, to be known as individuals. Yet it was difficult to manage this with over 60 students on the course and inevitably there were some students who remained (at least relatively) anonymous. Given that there are already more than 80 students registered for next year, finding a way to make sure all are engaged and supported will be a challenge.

This leads me to one final point. I mentioned earlier my own political commitment to the issues raised by this module, and I do need to be more aware of my own investment in the issues and consider how I might moderate my 'presence' in the classroom to allow for a more divergent range of engagement with the issues we discuss. But I need to do this without diluting my own passion and commitment to my subject, as this is one of the aspects of the course that seemed to be most highly valued by the students.

\section{Bibliography}

Althaus-Reid, Marcella, Indecent Theology: Theological perversions in sex, gender and politics (London: Routledge, 2000)

Althaus-Reid, Marcella, The Queer God (London: Routledge, 2003)

Althaus-Reid, Marcella, From Feminist Theology to Indecent Theology London: SCM Press, 2004)

Barron, Alexandra, 'Teaching Notes: Boys Don't Cry', Radical Teacher, 67, 2003, 43.

Bhopal, Kalwant, 'Teaching Women's Studies: the effects of 'race' and gender', Journal of Further and Higher Education, 26/2, 2002, 109-118.

Bok, Derek, 'Sensitivity to Women in the Contemporary Classroom' Derek Bok Center for Teaching and Learning, Harvard University, available online at: http://bokcenter.harvard.edu/docs/TFTwomen.html. No date. Accessed 13 September 2005.

Butler, Judith, Gender Trouble: Feminism and the Subversion of Identity (London: Routledge, 1990) 
Butler, Judith, Bodies that Matter: On the discursive limits of "sex", (London: Routledge, 1993).

Carey, Elaine 'Speaking About Power: Gender, History and the Urban Classroom', Radical Teacher, 67, 2003, 4- 8.

Collar, Julia, 'Speaking the Sexual' PRS-LTSN Journal, 1/2, 2002, 165-168.

Davis, Hilary, "They Like Me, They Really Like Me!" Critically Examining my Desire to be Loved by my Students', Philosophy of Education, 2000, available at http://www.uiuc.edu/EPS/PES-yearbook/2000/davis\%2000.pdf. Accessed 30 January 2006.

Desoto, Aureliano Maria (and McCready, Lance) Panel session on 'Queer Pedagogies' at the Queer Matters conference, King's College London, 29 May 2004.

Desoto, Aureliano Maria, 'A canvas of Desire: The Racialized and Sexualized Professor in the Classroom', MELUS, Vol. 30/2, 2005, 209-223.

Eyre, Linda, 'Compulsory Heterosexuality in a University Classroom' Canadian Journal of Education, 18/3, 1993, 273-284.

Faust-Sterling, Anne, Sexing the Body (New York: Basic Books, 2000).

Foucault, Michel, The Use of Pleasure (History of Sexuality: 2), (London: Penguin, 1992).

Freire, Paolo, Pedagogy of the Oppressed (London: Penguin, 1996).

Fry, Heather, Ketteridge, Steve, and Marshall, Stephanie 'Understanding Student Learning' in Heather Fry, Steve Ketteridge and Stephanie Marshall (eds.) A Handbook for Teaching and Learning in Higher Education, (London: Kogan Page, 2003).

Greer, Germaine, The Whole Woman (London: Anchor, 1999).

Halberstam, Judith, In a Queer Time \& Place: Transgender Bodies, Subcultural Lives (New York: New York University Press, 2005).

Halperin, David, Saint Foucault: Towards a Gay Hagiography (Oxford: Oxford University Press, 1995).

Kosofsky Sedgwick, Eve, Tendencies (London: Routledge, 1994).

Plante, Rebecca, Sexualities in Context, (Cambridge MA: Westview Press, 2006).

Rochlin, Martin, 'Heterosexuality Questionnaire', available at 
http://www.pinkpractice.co.u/quaire.htm. 1977. Accessed 31 May 2006.

Rubin, Gayle, 'Thinking Sex: Notes for a Radical Theory of the Politics of Sexuality' in Carol Vance (ed.) Pleasure and Danger (London: Harper Collins, 1992).

Schacht, Steven, 'Using a Feminist Pedagogy As a Male Teacher: The Possibilities of a Partial and Situated Perspective', Radical Pedagogy, available at http://radicalpedagogy.icaap.org/content/issue2 2/schadt.html. 2000. Accessed 22 September 2005.

Thomas, Calvin (ed.), Straight with a Twist: Queer Theory and the Subject of Heterosexuality (Urbana and Chicago: University of Illinois Press, 2000).

Tysome, Tony, 'Gay academics settle for wage "consolation prize", Times Higher Education Supplement, 26 May 2006.

Warren, Lee, 'Managing Hot Moments in the Classroom', Derek Bok Center for Teaching and Learning, Harvard University, available online at: http://bokcenter.harvard.edu/docs/hotmoments.html. No date. Accessed 13 September 2005.

Dee Amy-Chinn is a Senior Lecturer in Communication, Media and Culture at Oxford Brookes University. She has published on issues of gender and sexuality in Women: A Cultural Review, The European Journal of Cultural Studies, Feminist Media Studies and The Journal of Consumer Culture. She can be contacted at damychinn@brookes.ac.uk.

Contact information:

Dr Dee Amy-Chinn

Westminster Institute of Education

Oxford Brookes University

Harcourt Hill

Oxford

OX2 9AT

Tel: 01865488619 